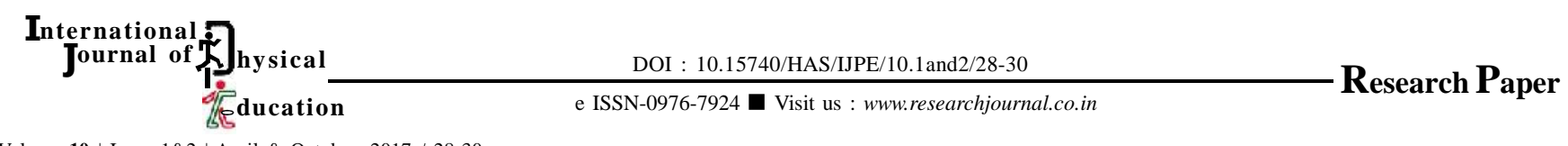

Volume 10 | Issue $1 \& 2$ | April \& October, 2017 | 28-30

\title{
Gender diffrence of achievement motivation in university kho- kho players
}

\section{MUKESH KUMAR VERMA}

Received : 12.08.2017; Revised : 18.09.2017; Accepted : 27.09.2017

Author for correspondence MUKESH KUMAR VERMA Department of Physical Education, Dr. Ram Manohar Lohia Avadh University, Faizabad (U.P.) INDIA

Email: mukeshverma369@gmail.com

\section{-ABSTRACT}

Background: The modern sports training lays a greater emphasis or preparing the athletes psychologically than physically and thus lot of emphases is being given to the psychological research dealing with psychological characteristics of the top level athletes. Male and female athletes (kho-kho players) not only defer physiologically but there are psychological differences also. Achievement motivation is one of the psychological parameter, which affects the performance of an athlete's (kho-kho player). Keeping in mind the determining role of achievement motivation in competitive performance the investigator decided to undertake this study. Material and methods : Fifteen (15) male and fifteen (15) female kho-kho players of Dr. Ram Manohar Lohia Avadh University Faizabad Uttar Pradesh were selected as subject for this study. To assess the achievement motivation of selected subject the Sports Achievement Motivation Test (SAMT) constructed by Kamlesh (1990) was used. The tool consisted of 20 test items to be answered by putting a mark of tick, t- test was used to compare the groups and significance of the values at 0.05 levels has been fixed. Result: Result of the study indicates that there is a significant difference in achievement motivation between university male and university female kho-kho players. On the basis of the result obtained in this study the investigator concludes the scores of achievement motivation between university male and university female kho-kho players. Conclusion: On the basis of the result obtained in this study the investigator concludes the scores that university male kho-kho players are significantly more motivated for their work as compared to university female kho-kho players.

- KEY WORDS : Achievement motivation, Sports achievement motivation test (SAMT), Psychological differences, Kho-kho player

- HOW TO CITE THIS PAPER : Verma, Mukesh Kumar (2017).Gender diffrence of achievement motivation in university kho-kho players. Internat. J. Phy. Edu., 10 (1\&2) : 28-30, DOI : 10.15740/HAS/IJPE/10.1 and $2 / 28-30$. 